\title{
Management of "brittle" diabetes with a preprogrammable implanted insulin pump delivering intraperitoneal insulin
}

\author{
D F Wood, K Goodchild, P Guillou, D J Thomas, D G Johnston
}

\begin{abstract}
Objective-Glycaemic control in a young woman with "brittle" diabetes.

Design-Use of a preprogrammable fully implanted pump (Infusaid) to deliver insulin intraperitoneally at variable rates, giving a total dose of about 60 units/24 h.

Setting-Endocrinology department in a teaching hospital.

Patient-Thirty year old woman with 15 years' history of "brittle" diabetes.

Main outcome measures-Glycated haemoglobin concentration; plasma glucose concentration.

Results-After implantation of the pump there was an immediate and sustained improvement in diabetic control. The patient's glycated haemoglobin concentration decreased from $15 \cdot 2 \%$ to $9.2 \%$ over seven months. Her daily glucose concentrations were in the range $3 \cdot 5-12 \mathrm{mmol} / 1$. She has not been admitted to hospital since implantation of the pump, which was eight months before the time of writing.

Conclusion-The implanted programmable intraperitoneal insulin pump may be of value in the management of patients with "brittle" diabetes in whom other attempts at glycaemic control have failed.
\end{abstract}

\section{Introduction}

The term "brittle" diabetes has been used to describe the disease in insulin dependent diabetic patients in whom considerable and unpredictable changes in glycaemic control occur. The lives of these patients are seriously disrupted by frequent episodes of ketoacidosis or hypoglycaemia, or both. ${ }^{12} \mathrm{We}$ report on a young woman with life threatening "brittle" diabetes who was treated successfully with a preprogrammable, fully implanted insulin pump delivering intraperitoneal insulin.

Departments of Clinic

Surgery, Imperial College of Science, Technology and Medicine, St Mary's Hospital Medical School, London W2 1NY

D F Wood, MRCP, lecturer $\mathrm{K}$ Goodchild, $\mathrm{MB}$, senior house officer

P Guillou, FRCS, professor of surgery

D G Johnston, FRCP, professor of clinical endocrinology

Mount Vernon Hospital, Northwood, Middlesex

D J Thomas, MRCP, consultant physician

Correspondence to: Dr Wood. episode of septicaemia and was stopped. Good diabetic control was achieved only with intravenous insulin so that over the following eight years continuous intra-

\section{Case report}

The patient, who at the time of writing was aged 30 , presented at the age of 15 with insulin dependent diabetes. Adequate glycaemic control was difficult to achieve from the start. The extent to which her life was disrupted by diabetes may be judged by the fact that in the intervening years she accrued more than 25 sets of notes in seven different hospitals. Between 1974 and 1980 she was admitted to hospital more than 90 times with diabetic ketoacidosis. Various methods of giving insulin were attempted over the years. Intermittent and continuous subcutaneous and intramuscular regimens were unsuccessful. Intraperitoneal insulin regimens were unsuccessful. Intraperitoneal insulin venous insulin infusions were given through numerous lines into the subclavian vein and other major vessels. Diabetic control improved and she had fewer hospital admissions. She did, however, have two episodes of deep venous thrombosis and one pulmonary embolism, and by 1988 venography and digital subtraction angiography showed occlusion of all major vessels, including the superior vena cava.

Glycaemic control subsequently deteriorated with intermittent intramuscular insulin, with glycated haemoglobin concentrations rising from $11.6 \%$ to $17 \cdot 6 \%$ (normal range $<8 \cdot 0 \%$ ). By the start of 1989 her life was threatened by daily hyperglycaemia (plasma glucose concentrations $30-40 \mathrm{mmol} / \mathrm{l}$ ), persistent ketosis, and frequent episodes of ketoacidotic coma, with peripheral venous access for treatment becoming increasingly difficult. Continuous intraperitoneal infusion of insulin was therefore considered as a treatment option.

The Infusaid Model 1000 Programmable Pump and Model 2100 Insulin Programmer (Infusaid, Norwood, Massachusetts, United States) were chosen for long term delivery of intraperitoneal insulin. To establish the efficacy of intraperitoneal treatment a Tenchkoff peritoneal dialysis catheter was first inserted. Good glycaemic control was obtained with continuous intraperitoneal infusion of insulin (Velosulin, Nordisk UK, East Grinstead, Sussex) at a rate of 2 units/hour with preprandial boluses of 12-16 units.

\section{Infusaid system}

The Infusaid system comprises a pump, which is implanted into the anterior abdominal wall, and a separate hand held programmer. The pump contains a $25 \mathrm{ml}$ reservoir that delivers insulin to an intraperitoneal catheter (fig 1). The insulin reservoir is filled transcutaneously through the raised central membrane. The

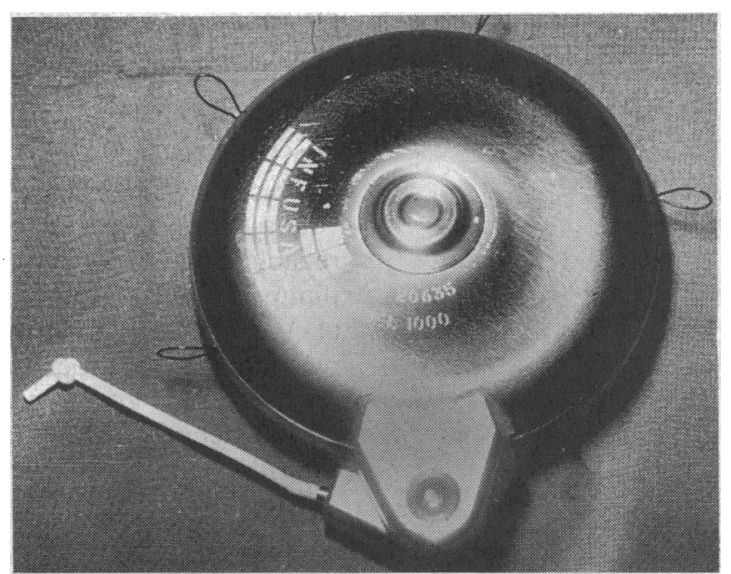

FIG 1-Infusaid Model 1000 implantable insulin pump (diameter $90 \mathrm{~mm}$, thickness $27 \mathrm{~mm}$, weight $275 \mathrm{~g}$ ) 


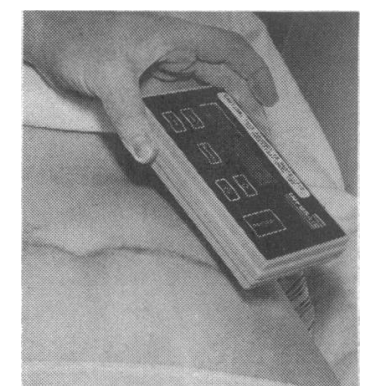

FIG 2-Hand held pump programmer for retrieving information regarding pump performance and programming rates of insulin delivery temporary catheter shown is removed at implantation and the permanent catheter attached to the side port. The catheter may be flushed through the side port membrane. Wire loops are used to anchor the pump into a subcutaneous pouch in the anterior abdominal wall. The rate of flow of insulin is regulated by standard pacemaker electronics. The insulin programmer transmits and receives information for programming the pump by telemetry. Up to six basal flow rates throughout 24 hours are possible with preprandial boluses as required. The upper and lower limits of the rates of insulin infusion are preset by the clinician.

The insulin preparation used with the Infusaid system is a specially developed soluble insulin (Hoechst 21 $\mathrm{PH}, 100 \mathrm{units} / \mathrm{ml}$ ), which is buffered by polyethylenepolypropylene glycol. This renders it stable at body temperature and prevents adherence to the pump and tubing.

\section{Clinical progress}

Insertion of the pump and intraperitoneal catheter was performed under general anaesthesia and the insulin infusion started in the manner recommended by the manufacturers. Five basal infusion rates were prescribed with boluses of 10-16 units before each meal, giving a total daily insulin dose of about 60 units/24 hours (table). Pump refills were performed every 4-5

Intraperitoneal insulin infusion rates over 24 hours. Insulin regimen currently in use is given to show variable infusion rates throughout the day

\begin{tabular}{cccc}
\hline Rate (units/h) & Time of day & $\begin{array}{c}\text { Minimum rate } \\
\text { (units/h) }\end{array}$ & $\begin{array}{c}\text { Maximum rate } \\
\text { (units/h) }\end{array}$ \\
\hline 3.0 & $0700-1100$ & $2 \cdot 0$ & $4 \cdot 0$ \\
1.5 & $1100-1500$ & 1.0 & 2.0 \\
1.0 & $1500-0100$ & 0.5 & 1.5 \\
0.5 & $0100-0400$ & 0.4 & 0.6 \\
0.3 & $0400-0700$ & 0.2 & 0.4
\end{tabular}

weeks. During this procedure a non-traumatic needle (Infusaid) was inserted transcutaneously into the pump's insulin reservoir, residual insulin removed, and the reservoir refilled with fresh insulin through the same needle. Information regarding pump performance and data relating to the previous month's treatment were retrieved from the programmer. Finally, insulin infusion rates for the succeeding month were programmed into the pump (fig 2).

The patient's glycaemic control improved dramatically. Fasting plasma glucose concentrations were between 3.5 and $7.0 \mathrm{mmol} / \mathrm{l}$, with a daily range of 3.5-12 mmol/l. Glycated haemoglobin concentration decreased from a preoperative value of $15 \cdot 2 \%$ to $8 \cdot 7 \%$ at three months and $\mathbf{9 \cdot 2 \%}$ at seven months after implantation. She had no episodes of symptomatic hypoglycaemia. It is perhaps of greater importance that during the eight months after implantation of the pump she had no hospital admissions, changed her job, and learned how to ski.

\section{Discussion}

This paper describes the successful treatment of a young woman with severe "brittle" diabetes and no reliable venous access by a preprogrammable implanted pump delivering intraperitoneal insulin. The ability of the the peritoneum to absorb insulin is well recognised, ${ }^{34}$ and there are theoretical advantages to this method of giving insulin. ${ }^{56}$ As a means of routine insulin delivery, however, the obvious drawbacks of external pumps and permanent, exterior peritoneal cathethers ${ }^{7.9}$ have meant that the practical use of the intraperitoneal route had to be delayed until the development of implantable pumps and stable insulin. The Infusaid system was developed initially as a constant flow device, and clinical trials of giving intravenous insulin by using these pumps were undertaken in the mid-1980s. ${ }^{11}$ Recently, more flexible variable rate devices delivering intraperitoneal insulin, such as the one described here, have been shown to be effective for treating patients with insulin dependent diabetes. ${ }^{12}$ Our experience suggests that this technique may be useful in the management of patients with "brittle" diabetes. The variable rate of insulin delivery is an important feature as treatment regimens can be carefully tailored to each individual patient's requirements. Furthermore, the physician is able to preset limits to the rate of insulin infusion, thus reducing the potential for manipulation of treatment by the patient.

Complications of this form of treatment are few. Catheter occlusions caused by omental adhesions have occurred in a small number of patients between three and six months after implantation. In general these are easy to treat transcutaneously and do not require removal of the pump (Infusaid trial, Update Number 1990-1, Massachusetts, United States). ${ }^{12}$ Infection has not proved to be a major problem and inappropriate insulin delivery has not been reported. There have been no incidents of pump failure (Infusaid trial). ${ }^{12}$

In conclusion, we have described the use of a new method of insulin delivery to treat a young patient with severe and ultimately life threatening insulin dependent diabetes. She experienced a dramatic improvement in diabetic control. The associated feeling of wellbeing and increased independence from hospital care have been reflected in her changes in lifestyle since receiving pump therapy. This form of treatment is expensive (it costs about $£ 8000$ for the pump and programmer) and is currently not appropriate for most insulin dependent diabetic patients. However, we think that it is extremely useful in the management of those patients in whom all other methods of treatment have been exhausted. Furthermore, the potential for development of this system in conjunction with glucose sensor techniques holds possibilities for improved management of all insulin dependent diabetic patients.

We thank Miss M McClaren of Infusaid for technical help and advice.

1 Tattersall RB. Brittle diabetes. Clinics in Endocrinology and Metabolism 1977;6: 403-19.

2 Gill GV, Walford S, Alberti KGMM. Brittle diabetes-present concepts. Diabetologia 1985;28:579-89.

3 Crossley K, Kjellstrand CM. Intraperitoneal insulin for control of blood sugar in diabetic patients during peritoneal dialysis . BMf 1971;30:269-70.

4 Schade DS, Eaton RP, Spencer W, Goldman R, Corbett WT. The peritoneal absorption of insulin in diabetic man: a potential site for a mechanical insulin delivery system. Metabolism 1979;28:195-7.

5 Schade DS, Eaton RP; Davis T, et al. The kinetics of peritoneal insulin absorption. Metabolism 1981;30:149-55.

6 Nelson JA, Stephen R, Landon ST, Wilson DE, Tyler FH. Intraperitoneal insulin administration produces a positive portal-systemic blood insulin gradient in unanesthetized unrestrained swine. Metabolism 1982;31: 969-72.

7 Irsigler R, Kritz H. Alternative routes of insulin delivery. Diabetes Care $1980 ; 3: 219-28$

8 Pozza G, Spotti D, Micossi P, et al. Long-term continuous intraperitoneal insulin treatment in brittle diabetes. $B M 7$ 1983;286:255-6.

9 Selam JL, Slingeneyer A, Saeidi S, et al. Experience with long-term peritoneal insulin infusion from external pumps. Diabetic Med 1985;2:41-4.

10 Selam JL. Development of implantable insulin pumps: long is the road. Diabetic Med 1988;5:724-33.

11 Paterson KR, Campbell IW, MacRury SM, Gilmour DG, MacCuish AC. Management of diabetes resistant to subcutaneous insulin with intravenous insulin via an implanted infusion pump. Scott Med J 1988;33:239-43.

12 Saudek CD, Selam JL, Pitt HA, et al. A preliminary trial of the programmable implantable medication system for insulin delivery. $N$ Englf Med 1989;321 574-9.

(Accepted 23 August 1990) 